TITLE:

\title{
Space-time variability of equatorial Kelvin waves and intraseasonal oscillations around the tropical tropopause
}

\author{
$\operatorname{AUTHOR}(\mathrm{S})$ :
}

Suzuki, Junko; Shiotani, Masato

\section{CITATION:}

Suzuki, Junko ...[et al]. Space-time variability of equatorial Kelvin waves and intraseasonal oscillations around the tropical tropopause. Journal of Geophysical Research: Atmospheres 2008, 113(D16): D16110.

ISSUE DATE:

2008-08-27

URL:

http://hdl.handle.net/2433/217094

\section{RIGHT:}

(C) 2008 American Geophysical Union. Further reproduction or electronic distribution is not permitted. 


\title{
Space-time variability of equatorial Kelvin waves and intraseasonal oscillations around the tropical tropopause
}

\author{
Junko Suzuki ${ }^{1,2}$ and Masato Shiotani ${ }^{1}$ \\ Received 1 October 2007; revised 2 April 2008; accepted 2 May 2008; published 26 August 2008.
}

[1] Using the ECMWF 40-year reanalysis data, large-scale variations of temperature and zonal wind around the tropical tropopause are investigated. From the space-time spectral analysis, two dominant spectral regions in the eastward propagating domain are found: one for Kelvin waves and the other for intraseasonal oscillations (ISOs). To investigate activities of Kelvin waves and ISOs we reconstructed the grid data for the two spectral windows and calculated the square amplitude at each grid point. Kelvin wave activities in zonal wind are vigorous during two seasons around February and July in the upper troposphere up to $100 \mathrm{hPa}$. However, the longitudinal maxima are found in the Eastern Hemisphere at $100 \mathrm{hPa}$ and in the Western Hemisphere at $150 \mathrm{hPa}$ and below. Activities calculated from the outgoing longwave radiation data for the Kelvin wave spectral window are different from those in zonal wind about their maximum longitudes and seasons. As the climatological background zonal wind in the upper troposphere is easterly in the Eastern Hemisphere and westerly in the Western Hemisphere, it seems that the difference of Kelvin wave activities between $100 \mathrm{hPa}$ and $150 \mathrm{hPa}$ is closely related to the background wind field affecting Kelvin wave propagation and dissipation. ISO activities in zonal wind at $100 \mathrm{hPa}$ are vigorous in the western Pacific during northern winter, and we may find relation to those in OLR. This indicates that the eastward moving disturbance with the ISO time scale is coupled with the organized convective system such as the Madden-Julian oscillation.

Citation: Suzuki, J., and M. Shiotani (2008), Space-time variability of equatorial Kelvin waves and intraseasonal oscillations around the tropical tropopause, J. Geophys. Res., 113, D16110, doi:10.1029/2007JD009456.

\section{Introduction}

[2] Recently some research efforts have been focusing on the tropical tropopause layer (TTL) where dynamical and chemical properties of the atmosphere gradually change from tropospheric to stratospheric features [e.g., Highwood and Hoskins, 1998]. They have been conducted mostly from the view point of stratosphere-troposphere exchange (STE), since the TTL is the primary exchange region of mass and chemical species between the troposphere and the stratosphere. In particular for water vapor, temperature variation in the TTL is one of the most important factors to control the dehydration mechanism of air entering the lower stratosphere from the upper troposphere.

[3] There are several dominant variations around the tropical tropopause. Among them, Kelvin waves have been well known as first captured on the basis of radiosonde data [e.g., Tsuda et al., 1994; Holton et al., 2001]. Space-time characteristics of Kelvin waves are described by periods of 10-20 days, zonal wave numbers $1-4$, vertical wavelength

\footnotetext{
${ }^{1}$ Research Institute for Sustainable Humanosphere, Kyoto University, Kyoto, Japan.

${ }^{2}$ Now at Institute of Observational Research for Global Change, Japan Agency for Marine-Earth Science and Technology, Yokosuka, Japan.

Copyright 2008 by the American Geophysical Union. 0148-0227/08/2007JD009456
}

of 3-4.5 km, and eastward phase speeds of $20-30 \mathrm{~m} \mathrm{~s}^{-1}$ [Tsuda et al., 1994]. The Kelvin wave around the TTL is supposed to play critical roles in STE of ozone [Fujiwara et al., 1998] and in dehydrating air entering the lower stratosphere from the upper troposphere [Fujiwara et al., 2001]. Recently Kelvin wave breaking in the tropopause region around $15-17 \mathrm{~km}$ became clear using the Equatorial Atmosphere Radar installed in Indonesia [Fujiwara et al., 2003]. Global Positioning System (GPS) radio occultation measurements have also been capable to detect Kelvin waves with high vertical resolution $(\sim 0.2 \mathrm{~km})$ [e.g., Randel and Wu, 2005; Ratnam et al., 2006].

[4] In the troposphere, tropical convective disturbance with the Kelvin wave structure in the dynamical field has often been assumed as a convectively coupled wave system. Takayabu [1994] using the infrared equivalent blackbody temperature data from the geostationary meteorological satellite and Wheeler and Kiladis [1999] using the satellite-observed outgoing longwave radiation (OLR) data showed that dominant variations were identified in specific wave number and frequency domains predicted under the linear theory for equatorial waves. Wheeler et al. [2000] also showed vertical structure of the convectively coupled Kelvin wave, and referred to its possible influence on the temperature and zonal wind fields up to the tropical lower stratosphere.

[5] The Madden-Julian oscillation (MJO) as an eastward propagating convective complex is another dominant 
disturbance with an intraseasonal time scale in the tropical atmosphere [e.g., Madden and Julian, 1994]; it also possibly extends up to the tropopause level [Madden and Julian, 1972; Kiladis et al., 2005] and affects the zonal mean tropical tropopause height [Son and Lee, 2007]. Nakazawa [1988] showed an observational result indicating that the MJO system consists of eastward propagating super cloud clusters. Wheeler and Kiladis [1999] further implied that the convective system embedded in the convectively coupled Kelvin wave is considered as a super cloud cluster. Moreover, Straub and Kiladis [2002] showed in a case study that the convectively coupled Kelvin wave was more active in the east of the MJO convective envelope than in the west. A possible influence due to the intraseasonal oscillation in relation to the dehydration mechanism around the TTL was documented by Eguchi and Shiotani [2004], using dynamical data from the ECMWF 40-year reanalysis (ERA-40) data and water vapor data from the Microwave Limb Sounder on board the Upper Atmosphere Research Satellite.

[6] In spite of their importance in variations around the TTL, seasonal and longitudinal characteristics of the Kelvin wave and the intraseasonal oscillation (ISO) have not been clearly documented yet. Using the ECMWF 15-year reanalysis data (ERA-15), Tindall et al. [2006] investigated zonally averaged seasonal and interannual variability of Kelvin waves at $100 \mathrm{hPa}, 70 \mathrm{hPa}$ and $50 \mathrm{hPa}$, and found maximum Kelvin wave activity at $100 \mathrm{hPa}$ around the solstices when tropical cloud activity maximizes. Using temperature data derived from the GPS radio occultation measurements for 2 years, Randel and $W u$ [2005] showed that planetary-scale Kelvin waves at $16.5 \mathrm{~km}$ are often linked to deep convective activity averaged over $60-180^{\circ} \mathrm{E}$, though the correspondence is not exact. As to the ISO, Zhou and Holton [2002] made an analysis using the tropical cold point tropopause (CPT) data during the Tropical Ocean-Global Atmosphere (TOGA) Coupled OceanAtmosphere Response Experiment (COARE) observation period from July 1992 to June 1993. They found in this limited data that negative CPT temperature anomalies located between the Indian Ocean and the western Pacific during northern winter led negative OLR anomalies by about 2-10 days. After all their efforts, these previous studies lacked climatological views of the longitudinal and seasonal variations of Kelvin waves and ISOs around the TTL, on which we will focus in this study using the long-term ERA-40 and OLR data.

[7] The data and methodology are written in section 2 . Section 3.1 describes general characteristics of the basic state around the TTL. On the basis of the space-time spectral analysis, a powerful tool to grasp dominant frequencies and wave numbers of waves or oscillations, section 3.2 presents dominant variations around the TTL. General features of the Kelvin wave and the ISO in relation to zonal wind and OLR are shown in section 3.3; here the ISOs are defined as oscillations in dynamical fields with intraseasonal time scales, irrespective of the oscillations being coupled with convections or not. Their seasonal and longitudinal variations are presented in sections 3.4 and 3.5, respectively. Summary and discussion are found in section 4 .

\section{Data and Methodology}

[8] In order to investigate temperature and wind field variations, we used the ERA-40 global analysis data that is available on a $2.5^{\circ} \times 2.5^{\circ}$ grid over the period for 45 years from September 1957 to August 2002. Detailed descriptions of the ERA-40 are given by Uppala et al. [2005]. As to the data quality around the tropical tropopause, Zhou et al. [2001] compared radiosonde soundings with the ERA-15 data, a predecessor of the ERA-40, and found that the ERA-15 is appropriate to investigate meteorological variations around the tropical tropopause region. Recently the ERA-40 data has been widely used for studies on the tropical atmosphere including the troposphere and the stratosphere [e.g., Dima and Wallace, 2007]. The original data is provided for every $6 \mathrm{~h}$, but in this study we averaged on a daily basis. There are 23 pressure levels from $1000 \mathrm{hPa}$ to $1 \mathrm{hPa}$, and we focused mostly on the tropical tropopause region, around which the vertical spacing is about $2-2.5 \mathrm{~km}$ as estimated from average altitude at $150 \mathrm{hPa} \sim 14.2 \mathrm{~km}$, $100 \mathrm{hPa} \sim 16.6 \mathrm{~km}$ and $70 \mathrm{hPa} \sim 18.6 \mathrm{~km}$. In comparison with the use of the rawinsonde data [e.g., Fujiwara et al., 1998], the vertical resolution may not be sufficient to describe a rapid change in the vertical wave structure such as the change in the Kelvin wave around the TTL. However, the horizontal resolution would be enough to draw the wave structure, because the background field is less variable in horizontal direction.

[9] The daily OLR data from the NOAA polar-orbiting satellites is also available on a $2.5^{\circ} \times 2.5^{\circ}$ grid over the period from January 1979 to August 2002; it is used as a proxy of convective activity. For most meteorological parameters statistical operations such as averaging are carried out over the equator between $5^{\circ} \mathrm{S}$ and $5^{\circ} \mathrm{N}$. Exceptionally for the OLR data it is estimated between $10^{\circ} \mathrm{S}$ and $10^{\circ} \mathrm{N}$, because organized convection is sometimes located away from the equator.

[10] As will be shown in Figure 1, there are many remarkable disturbances propagating eastward at $100 \mathrm{hPa}$ over the equator. To grasp the dominant periodicity and zonal wave number, we have performed the space-time spectral analysis as followed by the method of Wheeler and Kiladis [1999]. For details, see Wheeler and Kiladis [1999], but here we briefly describe an outline of the analysis method. First, we remove the first, second and third harmonics of the annual cycle in the time series data. Because the Kelvin wave has a symmetric structure with respect to the equator, symmetric-antisymmetric decomposition is performed for the data; the gridded field as a function of latitude, $\varphi$, can be written as $\mathrm{X}(\varphi)=[\mathrm{Xa}(\varphi)+$ $\mathrm{Xs}(\varphi)]$, where $\mathrm{Xs}(\varphi)=[\mathrm{X}(\varphi)+\mathrm{X}(-\varphi)] / 2$ is the symmetric component, and $\mathrm{Xa}(\varphi)=[\mathrm{X}(\varphi)-\mathrm{X}(-\varphi)] / 2$ is the antisymmetric component. Then the space-time spectral analysis is performed to the time series for overlapped 92 days starting on 30 days before the beginning of each month. For example, the starting date for the analysis of January is 2 December in the previous year. In order to remove red noise, power spectra calculated from the symmetric data (hereafter symmetric power spectra) are divided by those calculated from the original (symmetric + antisymmetric) data (hereafter background power spectra). Since the raw power spectra have large estimated errors especially in high frequency, they are smoothed with use of a 1-2-1 filter in wave number and frequency. Such results will be found in Figure 4. 
(a) Temperature $100 \mathrm{hPa} 1990$

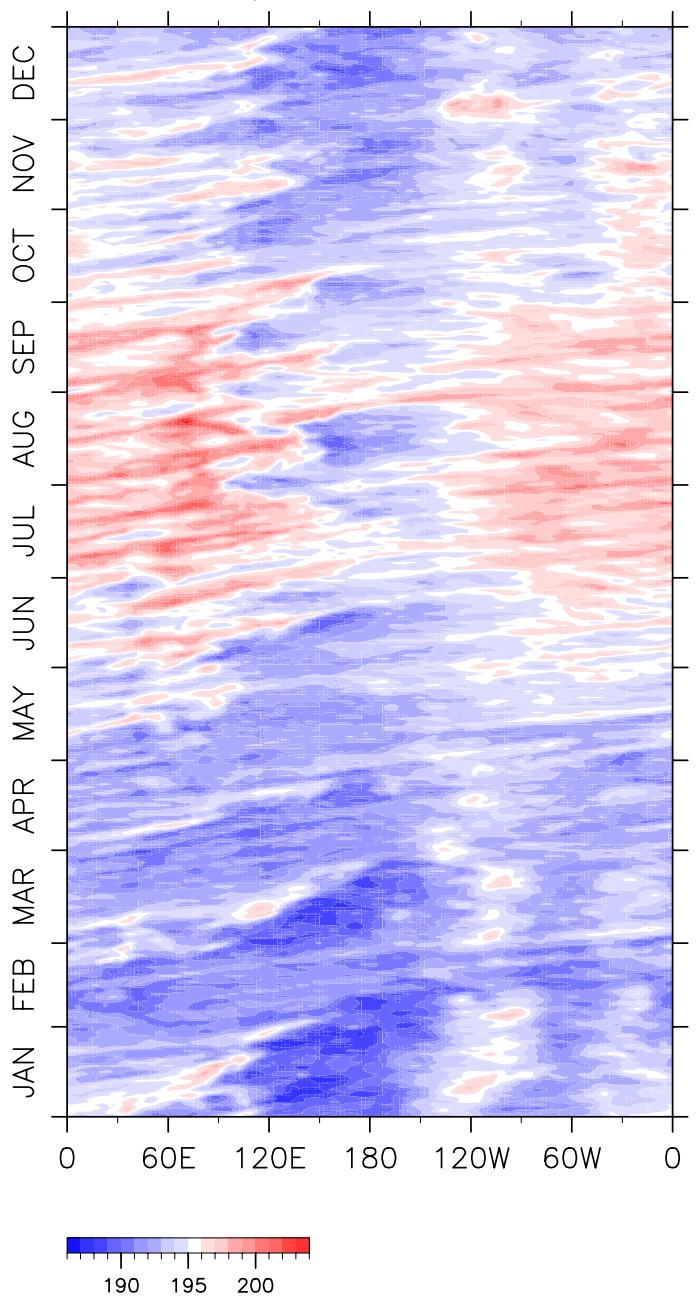

$(\mathrm{K})$ (b) Zonal wind $100 \mathrm{hPa} 1990$

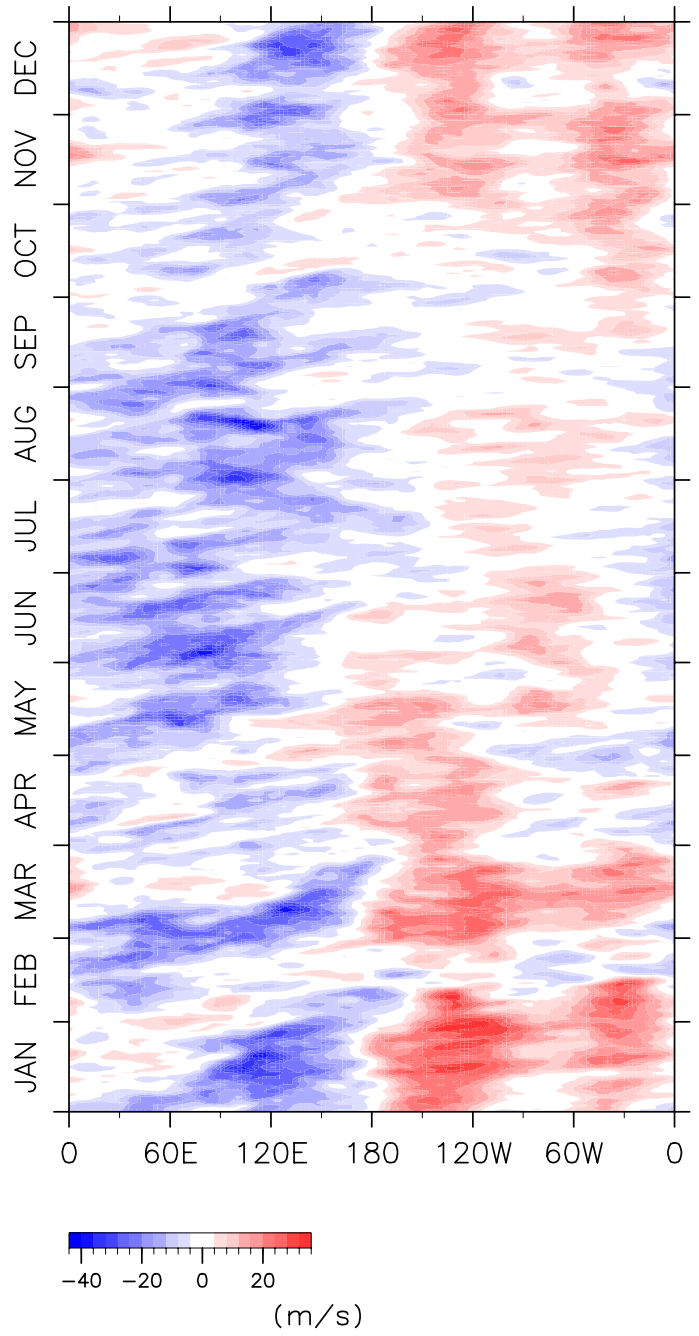

Figure 1. Longitude-time sections of (a) temperature and (b) zonal wind at $100 \mathrm{hPa}$ averaged over latitudes $5^{\circ} \mathrm{S}-5^{\circ} \mathrm{N}$ in 1990 from the ERA-40 reanalysis data.

[11] From results of the spectral analysis, we define two major spectral domains corresponding to the Kelvin wave and the ISO. The longitudinal and seasonal variations are investigated on the basis of the filtered grid data which are calculated by the inverse Fourier transform for the two major spectral domains of our interest. Then, activity for the Kelvin wave and the ISO is examined at each grid point as the square amplitude of the reconstructed data.

\section{Results}

\subsection{Basic State}

[12] Figure 1 shows Hovmöller diagrams (longitude-time sections) for temperature (Figure 1a) and zonal wind(Figure 1b) at $100 \mathrm{hPa}$ averaged over latitudes $5^{\circ} \mathrm{S}$ and $5^{\circ} \mathrm{N}$ in 1990 . We chose this year as a normal case from the view point of the El Niño-Southern Oscillation (ENSO) cycle. In Figure 1a for the temperature field around the tropical tropopause region there are many remarkable disturbances propagating eastward throughout the year with a typical time scale of about a week or longer. During northern winter, however, there sometimes appear disturbances associated with cold anomalies propagating eastward with a slower phase speed; for instance, cold anomalies around $60^{\circ} \mathrm{E}$ in late February propagate eastward to the dateline in mid-March. In general the basic temperature field is colder during northern winter from December to April than during northern summer from June to September; the longitudinal contrast can be clearly seen as being colder in the equatorial western and central Pacific between $120^{\circ} \mathrm{E}$ and $150^{\circ} \mathrm{W}$.

[13] Figure 1b shows characteristics of zonal wind variations at $100 \mathrm{hPa}$. There are also eastward propagating disturbances throughout the year with a time scale of about a week or longer. Lower-frequency variations can also be seen in the wind field; the strong easterly around $60^{\circ} \mathrm{E}$ in late February propagates eastward to the dateline in midMarch as similarly seen in Figure 1a. The basic wind field is easterly in the Eastern Hemisphere and westerly in the Western Hemisphere throughout the year.

[14] Some climatological features in the horizontal wind and OLR fields are briefly summarized before showing results of the spectral analysis. These background conditions are very important to understand activities in Kelvin waves and ISOs in relation to their variation and propagation 
(a) Climatological Zonal wind $100 \mathrm{hPa}$

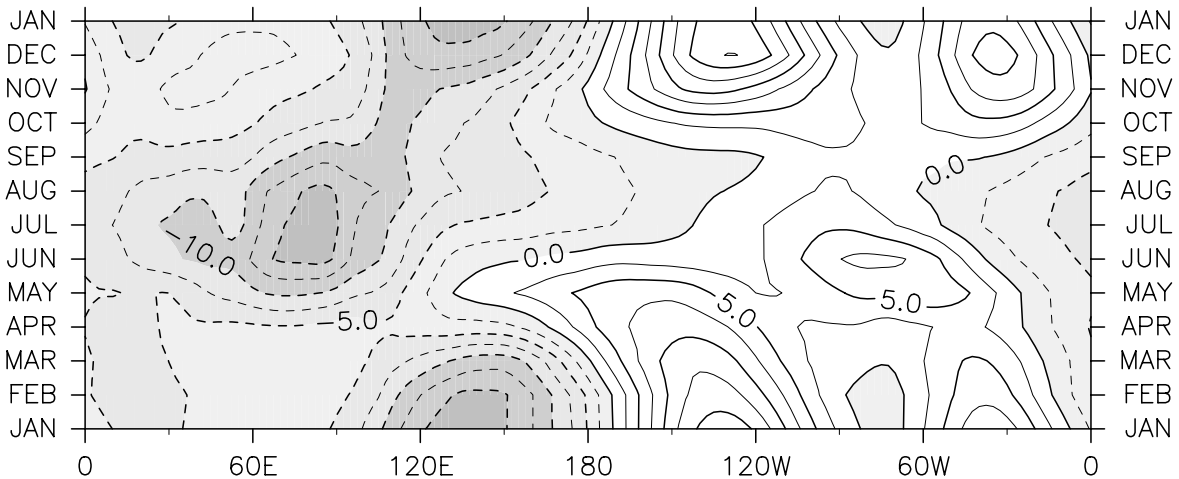

(b) Zonal wind all seasons

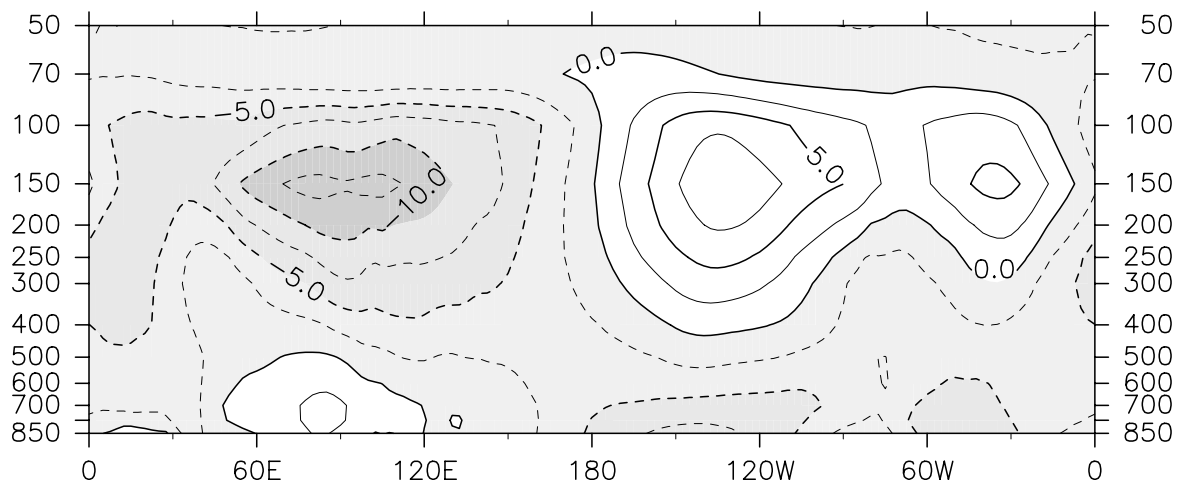

Figure 2. (a) A longitude-time section of the climatological zonal wind at $100 \mathrm{hPa}$ averaged over latitudes $5^{\circ} \mathrm{S}-5^{\circ} \mathrm{N}$ and periods $1957-2002$ from the ERA-40 reanalysis data. Contour interval is $2.5 \mathrm{~m}$ $\mathrm{s}^{-1}$ with negative contours dashed. (b) A longitude-height section of climatological zonal winds averaged over latitudes $5^{\circ} \mathrm{S}-5^{\circ} \mathrm{N}$ and all months. Contour interval is $2.5 \mathrm{~m} \mathrm{~s}^{-1}$ with negative contours dashed.

properties, which will be discussed in sections 3.4 and 3.5. Figure 2 a shows the monthly mean zonal wind climatology at $100 \mathrm{hPa}$ averaged over 45 years during 1957-2002 and latitudes between $5^{\circ} \mathrm{S}$ and $5^{\circ} \mathrm{N}$. In general the zonal wind is easterly in the Eastern Hemisphere and westerly in the Western Hemisphere throughout the year, probably because of response to convective cloud activities over the Pacific warm pool. Paying attention to the easterly wind, we found it is strong in two seasons: one is during northern winter from November to March over Indonesia and the western Pacific, and the other is during northern summer from May to
September between the Indian Ocean and the western Pacific. This seasonal variation of the easterly wind in the Eastern Hemisphere might be caused by the Australian monsoon and the Indian/Southeast Asian monsoon, respectively [Webster et al., 1998]. Figure 2b shows a longitude-height cross section for the annual mean zonal wind. The east-west contrast of the background zonal wind as shown in Figure $2 \mathrm{a}$ is extended in the upper troposphere between $250 \mathrm{hPa}$ and $100 \mathrm{hPa}$.

[15] Figure 3 shows a longitude-time section of the monthly mean OLR climatology averaged over 23 years

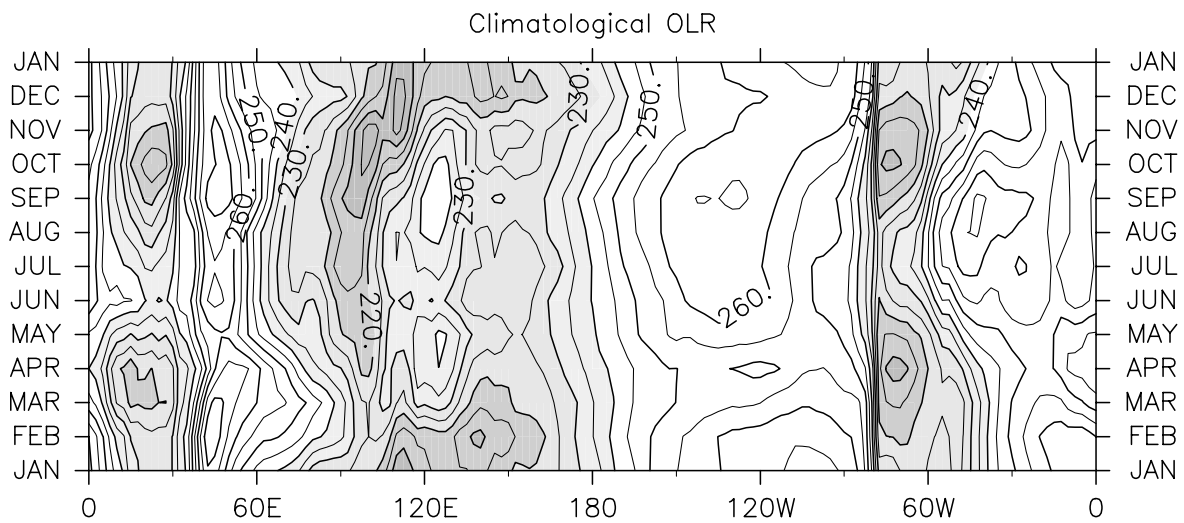

Figure 3. A longitude-time section of the climatological OLR averaged over latitudes $10^{\circ} \mathrm{S}-10^{\circ} \mathrm{N}$ and periods 1979-2002 from the NOAA satellites data. Contour interval is $5 \mathrm{~W} \mathrm{~m}^{-2}$, and shading begins below $240 \mathrm{~W} \mathrm{~m}^{-2}$. 
(a) Temperature SYM/BAK $100 \mathrm{hPa}$

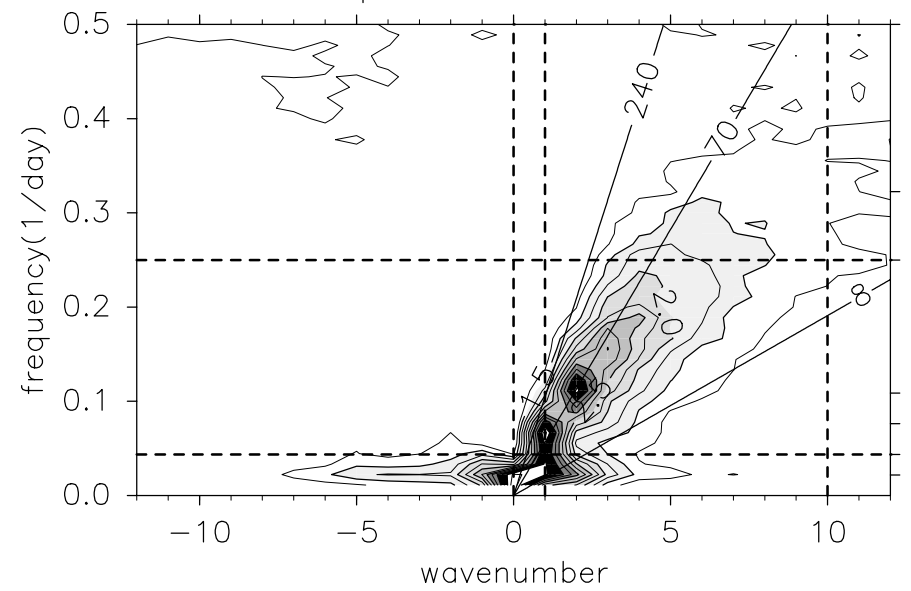

(b) Zonal wind SYM/BAK $100 \mathrm{hPa}$

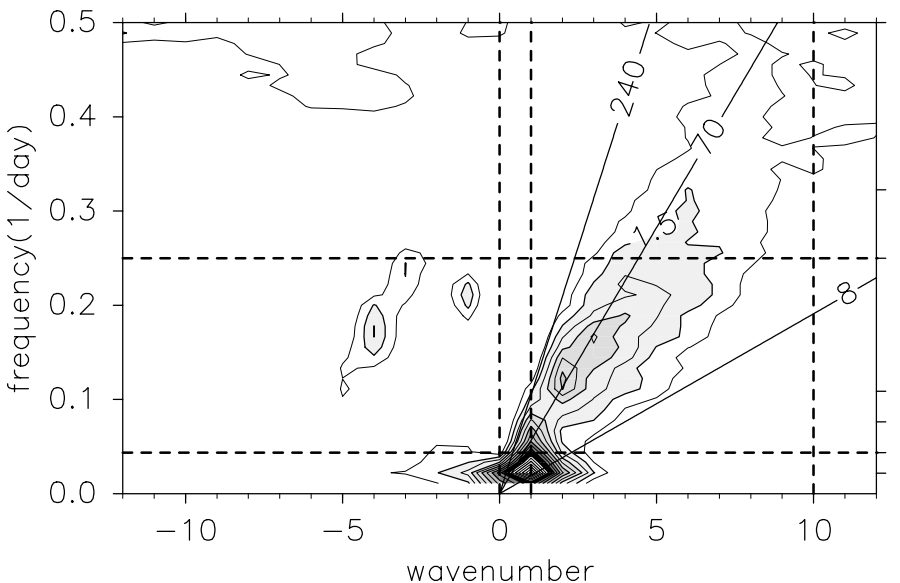

2.0

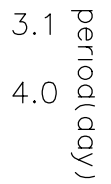

9.2

13.1

23.8

2.0

3.1 व

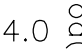

高

9.2

13.1

23.8

Figure 4. Zonal wave number-frequency power spectral ratios of the symmetric power spectra divided by the background power spectra at $100 \mathrm{hPa}$ of (a) temperature and (b) zonal wind calculated for the period from 1957 to 2002 . For each component, the power spectra were summed over latitudes $5^{\circ} \mathrm{S}-5^{\circ} \mathrm{N}$. Solid lines are dispersion curves for the equatorial Kelvin wave corresponding to three different equivalent depths of $h=8,70$, and $240 \mathrm{~m}$. Vertical dotted lines are zonal wave numbers $s=0,1$, and 10 . Horizontal dotted lines are periods for 4 and 23 days. Contour lines begin at 1.25 with an increment of 0.25 . Shading begins over 1.5 .

during $1979-2002$ and between $10^{\circ} \mathrm{S}$ and $10^{\circ} \mathrm{N}$. There are three convectively active regions: Africa, the Indian Ocean and the western Pacific, and South America. Convective activities in these regions could influence the zonal wind up to the tropopause level at $100 \mathrm{hPa}$ (Figure $2 \mathrm{~b}$ ). In addition, the organized convective system releasing latent heat works as an energy source for waves such as the Kelvin wave to propagate vertically. Wheeler et al. [2000] suggested that the eastward moving convective system with specific wave numbers, frequencies and equivalent depths has dynamical structures similar to those due to Kelvin waves with their vertical extension up to the tropopause in equatorial latitudes. The relationship between Kelvin waves and convective activities will be discussed in section 3.4.

\subsection{Power Spectral Analysis}

[16] Figure 4 shows contour plots of the symmetric power spectrum divided by the background power spectrum for temperature (Figure 4a) and zonal wind (Figure $4 \mathrm{~b}$ ) at 100 $\mathrm{hPa}$. An equivalent depth dispersion relation which can be transformed into a phase speed of internal gravity waves is also plotted. In Figure $4 a$ for the temperature, there exist three dominant spectral peaks in the eastward propagating domain. Two of them are lined up in a spectral domain for zonal wave numbers from 1 to 8 , periods from 4 to 23 days, and equivalent depths from 8 to $240 \mathrm{~m}$, when we look at a contour line of 1.5. In this region, two prominent peaks are seen; one is located at wave number one and a period around 15.3 days, and the other at wave number two and a period around 9.2 days. Since there is no corresponding spectral peak in the westward propagating domain at the same wave number and frequency, these peaks are recognized as traveling waves, and will be found eventually to be Kelvin waves. The two spectral peaks are seen along the equivalent depth of about $h=70 \mathrm{~m}$ corresponding to the phase speed $c=26 \mathrm{~m} \mathrm{~s}^{-1}$.

[17] The other dominant spectral region is found in wave numbers from 1 to 4 and periods around 23-46 days, which probably corresponds to the MJO. As Kiladis et al. [2005] suggested, the dynamical structure of the MJO could reach 
(a) Kelvin $100 \mathrm{hPa}$

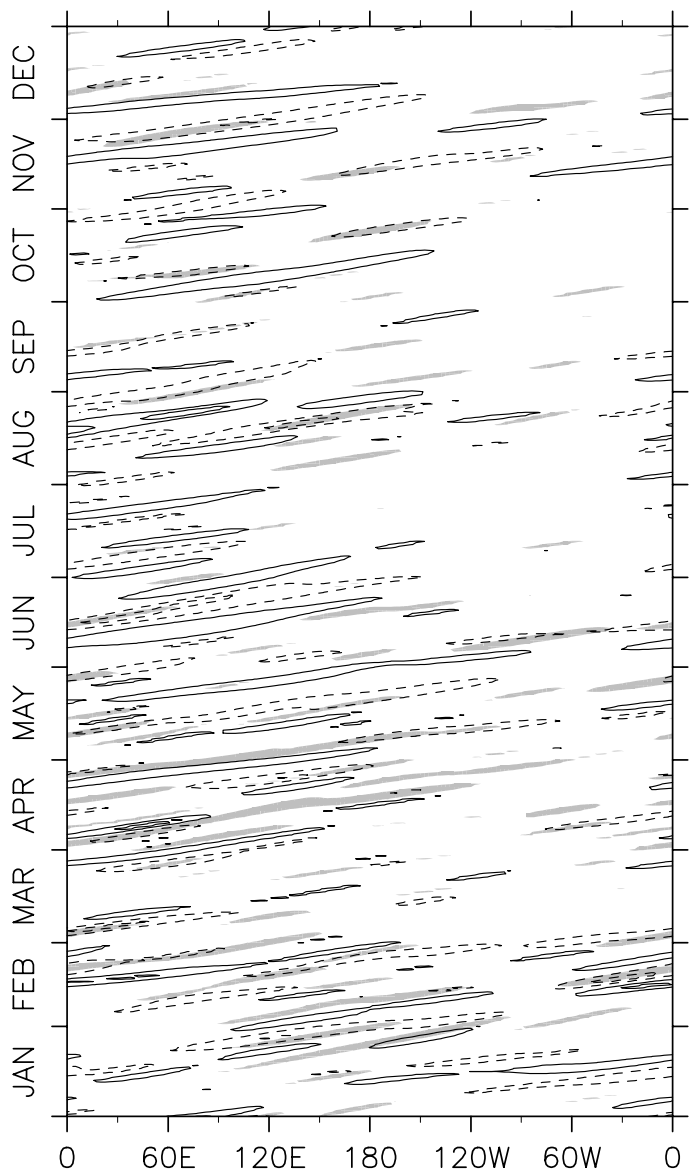

(b) ISO $100 \mathrm{hPa}$

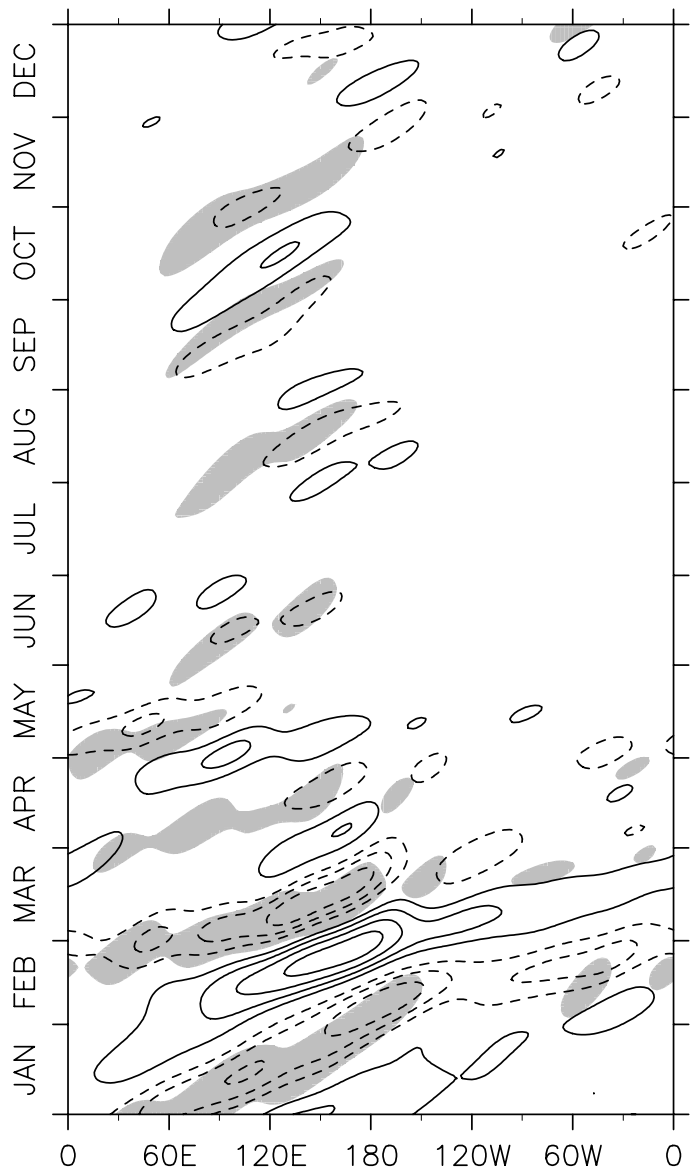

Figure 5. As in Figure 1b except for (a) the Kelvin wave component and (b) the ISO component of zonal wind (contours) with the corresponding OLR component superimposed on each (shadings). A contour interval is $4 \mathrm{~m} \mathrm{~s}^{-1}$; negative contour lines are dashed, and zero contour lines are omitted. The shading indicates values less than $\sim 5 \mathrm{~W} \mathrm{~m}^{-2}$.

the tropopause. Separation of the two spectral peaks at wave number one with periods around 15.3 days and around 23-46 days is not clear, since the data length for the spectral analysis would be short (92 days). However, by taking account of results for the zonal wind in the following, we select the period 23 days as a boundary between the Kelvin wave and ISO domains.

[18] In Figure $4 \mathrm{~b}$ for the zonal wind, there exist two dominant spectral regions in the eastward domain. A slight difference from results of the temperature field (Figure 4a) is that the spectral peak seen around wave number one and period 15.3 days is smeared out. One spectral region is aligned along specific equivalent depths from 8 to $240 \mathrm{~m}$, and has characteristics of wave numbers from 1 to 7 and periods from 4 to 23 days, when we look at a contour line of 1.5. We further performed the space-time cross-spectral analysis between the temperature and zonal wind fields at $100 \mathrm{hPa}$, and found that the phase for the temperature precedes that for the zonal wind about $90^{\circ}$ around this spectral region (not shown). This phase difference is consistent with the theoretical structure of the Kelvin wave [Andrews et al., 1987]. The other dominant peak is also found in wave numbers from 1 to 4 and periods around
23-46 days, which is similar to that found in the temperature analysis for the MJO.

[19] From the spectral analyses above, we recognize that the two dominant spectral peaks in the eastward propagating domain are due to the Kelvin wave and the ISO. Here we define the two domains as follows: one has zonal wave numbers from 1 to 10 , periods (frequencies) from 4 to 23 days (from 0.0435 to $0.250 \mathrm{~d}^{-1}$ ), and equivalent depths (phase speeds) from 8 to $240 \mathrm{~m}$ (from 8.9 to $48.5 \mathrm{~m} \mathrm{~s}^{-1}$ ) for the Kelvin wave, and the other has wave numbers from 1 to 10 and periods (frequencies) from 23 to 92 days (from 0.0109 to $0.0435 \mathrm{~d}^{-1}$ ) for the ISO, respectively. Then we will examine longitudinal and seasonal relationships between the dynamical fields and convection in the following subsections. Note that the spectral window defined in this study is rather wider than that used by Wheeler and Kiladis [1999] who defined it from the spectral analysis of the OLR field.

[20] In the following we will mostly focus on the zonal wind field, not on the temperature field, because the temperature structure at $100 \mathrm{hPa}$ changes largely with season; however some results from the temperature field will be included in Figures 7 and 10 for the annual mean. As Seidel et al. [2001] showed that the $100 \mathrm{hPa}$ level has the tropospheric property during northern winter and the stratospheric one during 
(a) Zonal wind Kelvin activity $100 \mathrm{hPa}$

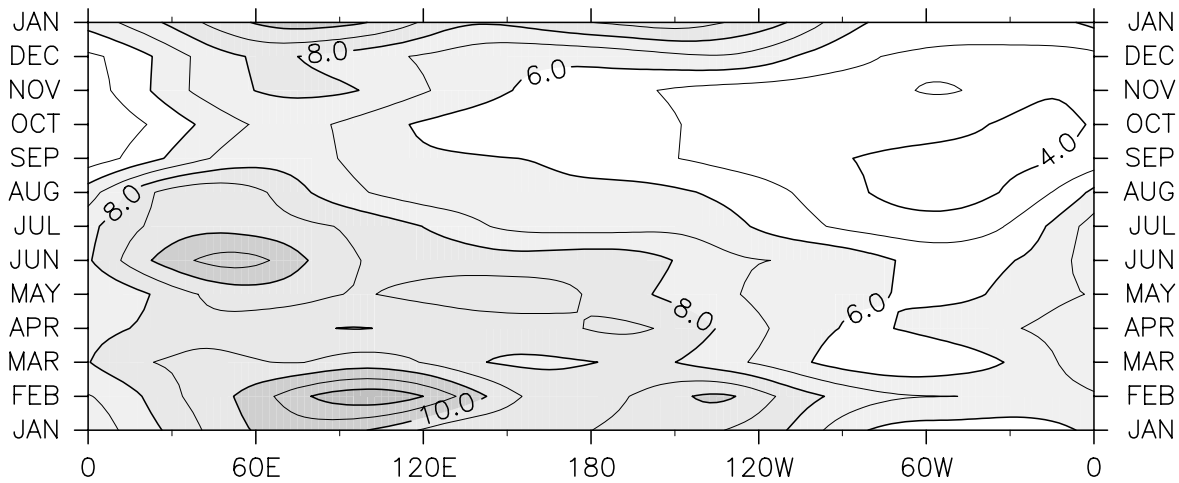

(b) Zonal wind Kelvin activity $150 \mathrm{hPa}$

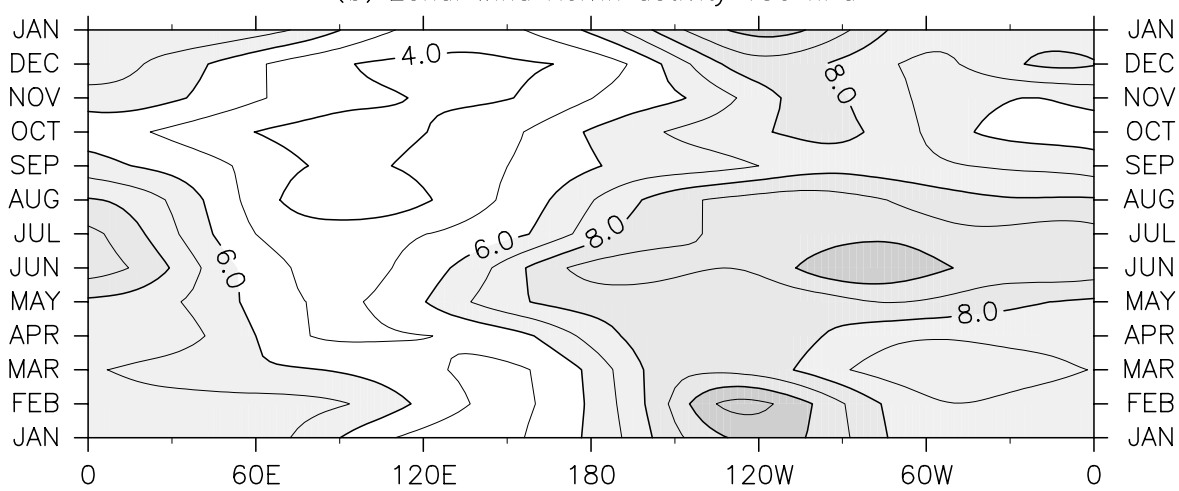

Figure 6. Longitude-time sections of the climatological Kelvin wave activities defined as square amplitudes of zonal wind averaged over latitudes $5^{\circ} \mathrm{S}-5^{\circ} \mathrm{N}$ (a) at $100 \mathrm{hPa}$ and (b) at $150 \mathrm{hPa}$. A contour interval is $1.0 \mathrm{~m}^{2} \mathrm{~s}^{-2}$, and shading begins above $6.0 \mathrm{~m}^{2} \mathrm{~s}^{-2}$.

northern summer. In such a condition, Kelvin wave amplitudes in the temperature field at $100 \mathrm{hPa}$ are expected to be larger during northern summer than during northern winter because of a change in the Brunt-Väisälä frequency $N$ inferred from temperature profiles; to estimate wave energy the change in $N$ is also crucial [Andrews et al., 1987]. Moreover the estimation of $N$ from the temperature profile with vertically sparse spacing is not appropriate around the tropopause, and it would be difficult to investigate seasonal variations of wave energy appropriately. In comparison with the temperature field, the zonal wind field is not affected so seriously by seasonal variations of $N$, and it is suitable to analyze the Kelvin wave and ISO activities.

[21] Results from the spectral analysis at other pressure levels are not shown here, but it can be safely said that dominant spectral distributions in the temperature and zonal wind fields between $250 \mathrm{hPa}$ and $150 \mathrm{hPa}$ are similar to those seen at $100 \mathrm{hPa}$. As will be shown later in a related plot (Figure 10) the power spectra of ISOs are also large in the upper troposphere between $250 \mathrm{hPa}$ and $100 \mathrm{hPa}$. In the following we will further investigate space-time variations of the Kelvin and ISO activities around the tropical tropopause.

\subsection{Filtering for Kelvin Waves and ISOs}

[22] Using the Fourier transform and the inverse Fourier transform for the enclosed spectral regions as mentioned in section 3.2, the grid data are reconstructed as representing longitude-time variations of Kelvin waves and ISOs. Figure 5 shows Hovmöller diagrams of the zonal wind as Figure $1 \mathrm{~b}$ but for only the Kelvin wave spectral component (Figure 5a) and the ISO spectral component (Figure 5b). At the same time the OLR field with the use of the same spectral filter is superimposed on each. As already mentioned to Figure 1 space-time variations seen in this year would be typical. Climatological features averaged over the whole data period will be shown in sections 3.4 and 3.5. In Figure 5a zonal wind anomalies of the Kelvin wave are ubiquitously observed at $100 \mathrm{hPa}$ around the tropical tropopause as shown in Figure $1 \mathrm{~b}$. The easterly and westerly anomalies are propagating eastward throughout the year, and they are particularly vigorous in the Eastern Hemisphere and during northern winter and spring. In other words, the Kelvin wave is inactive in the Western Hemisphere during northern summer and autumn at $100 \mathrm{hPa}$. Sometimes the easterly anomalies are seen in accordance with the negative OLR anomalies, but it is not always the case.

[23] Figure 5b shows a Hovmöller diagram of the zonal wind as Figure 5a but for the ISO spectral component. In particular, anomalies of the ISO propagating eastward are clearly seen in the Eastern Hemisphere during northern winter. For example, prominent ISO anomalies in the easterly wind first appear around the Indian Ocean in late February, and propagate eastward. The amplitude is generally larger than that of the Kelvin wave. Disturbances with shorter lifetime and smaller amplitude in the Eastern Hemisphere are also seen in other seasons. The easterly wind is usually coincident with the negative OLR anomaly, and the westerly wind is seen at out-of-phase times about 20-30 days forward 
(a) Zonal wind Kelvin activity all seasons

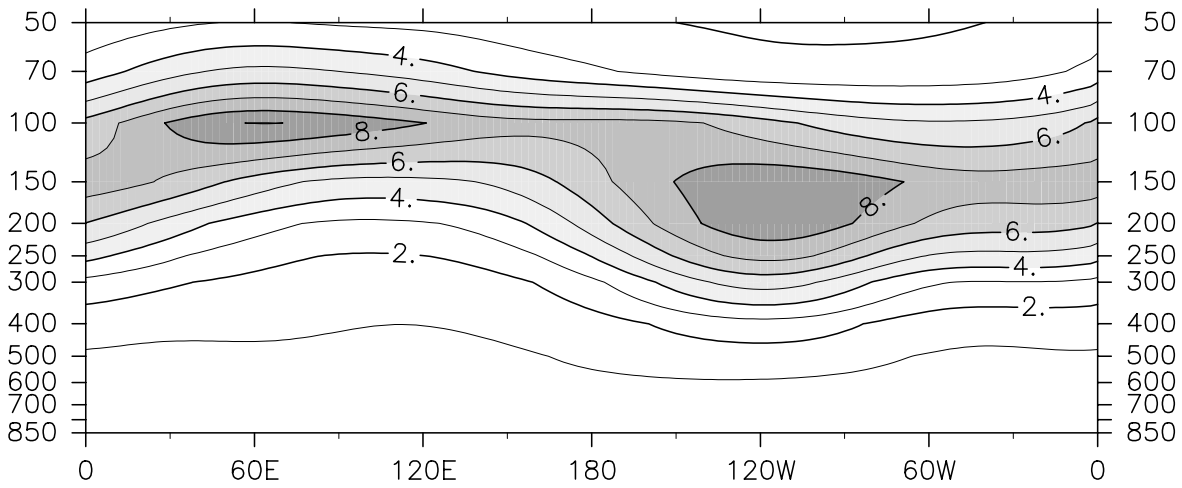

(b) Temp Kelvin activity all seasons

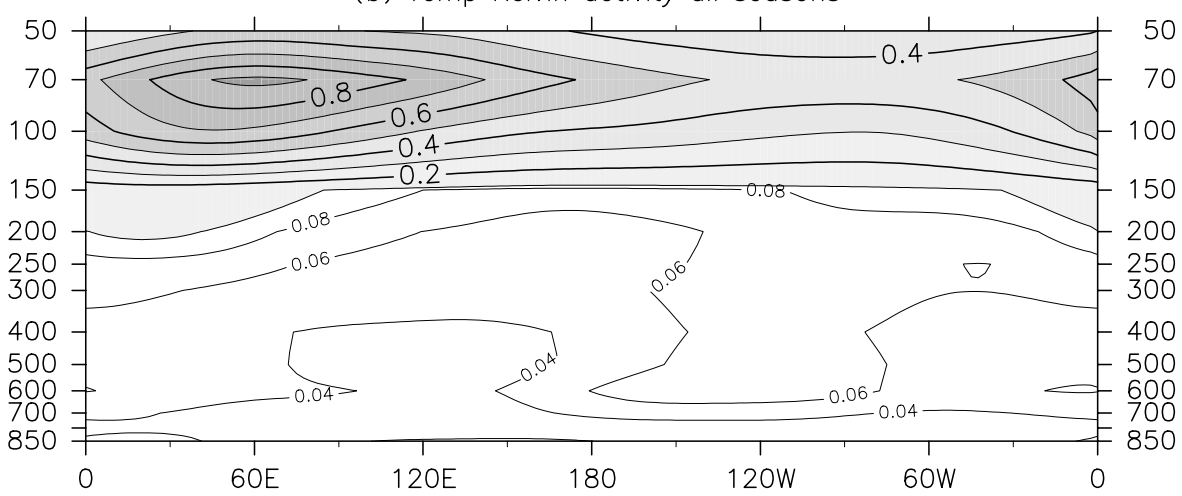

Figure 7. Longitude-height sections of the annual mean Kelvin wave activities of (a) zonal wind and (b) temperature. In Figure 7a, a contour interval is $1.0 \mathrm{~m}^{2} \mathrm{~s}^{-2}$, and shading begins above $4.0 \mathrm{~m}^{2} \mathrm{~s}^{-2}$. In Figure $7 \mathrm{~b}$, a contour interval is $0.1 \mathrm{~K}^{2}$, and $0.04,0.06$, and $0.08 \mathrm{~K}^{2}$ lines are also drawn. Shading begins above $0.1 \mathrm{~K}^{2}$.

or behind. After the ISO disturbance passes through the dateline, the phase speed increases and the amplitude decreases. During January to February the easterly region with the negative OLR anomaly propagates eastward up to $150^{\circ} \mathrm{W}$ at a phase speed of about $4-8 \mathrm{~m} \mathrm{~s}^{-1}$. Then the easterly wind anomaly with much less OLR anomaly in the Western Hemisphere than in the Eastern Hemisphere continues to propagate and increases its speed over $15 \mathrm{~m} \mathrm{~s}^{-1}$ in late February. This speed alteration is similar to that usually identified for the MJO [e.g., Madden and Julian, 1994]. As some studies suggested that the MJO system possibly affects the tropopause [e.g., Madden and Julian, 1972; Kiladis et al., 2001], we consider that the ISO activity in the TTL could be controlled by the MJO activity.

\subsection{Kelvin Wave Activity}

[24] To investigate space-time variations of the Kelvin wave activity, we calculate the square amplitude at each grid point. Then it is monthly averaged over latitudes $5^{\circ} \mathrm{S}$ and $5^{\circ} \mathrm{N}$ for zonal wind and over latitudes $10^{\circ} \mathrm{S}$ and $10^{\circ} \mathrm{N}$ for OLR. Figure $6 \mathrm{a}$ at $100 \mathrm{hPa}$ and Figure $6 \mathrm{~b}$ at $150 \mathrm{hPa}$ show time-longitude sections of the climatological Kelvin wave activity in zonal wind averaged over the period 1957-2002. Most vigorous Kelvin wave activities at $100 \mathrm{hPa}$ are found in the Eastern Hemisphere especially between $60^{\circ} \mathrm{E}$ and $140^{\circ} \mathrm{E}$ during January to March, and the second maxima in June between $30^{\circ} \mathrm{E}$ and $80^{\circ} \mathrm{E}$. The inactive time and longitude is seen during September and October between $80^{\circ} \mathrm{W}$ and $0^{\circ} \mathrm{W}$. As a source of wave activity in the stratosphere, Tindall et al. [2006] using the ERA-15 data found that zonally averaged Kelvin wave activity at $100 \mathrm{hPa}$ was maximum in either from December to February and from June to August, which agrees with our result in a zonal mean sense.

[25] On the contrary at $150 \mathrm{hPa}$, vigorous Kelvin wave activities are found in the Western Hemisphere especially between $130^{\circ} \mathrm{W}$ and $60^{\circ} \mathrm{W}$. The maxima during January to March between $130^{\circ} \mathrm{W}$ and $100^{\circ} \mathrm{W}$ are larger than those during May to July. Though the maximum values and their seasonality at $150 \mathrm{hPa}$ are almost similar to those at $100 \mathrm{hPa}$, the longitudinal distribution is quite different; the active longitudes are found in the Eastern Hemisphere at $100 \mathrm{hPa}$, but in the Western Hemisphere at $150 \mathrm{hPa}$. Observations on Kelvin waves have been done mostly in the Eastern Hemisphere as introduced in section 1, but there is evidence for the existence as shown by Fujiwara et al. [2001] and Hasebe and Koyata [2004] using radiosonde data at San Cristóbal Island $\left(0.9^{\circ} \mathrm{S}, 89.6^{\circ} \mathrm{W}\right)$ in the eastern Pacific. The seasonal and longitudinal variations of Kelvin wave activities at $200 \mathrm{hPa}$ and $250 \mathrm{hPa}$ are basically similar to those at $150 \mathrm{hPa}$ except that the square amplitudes are smaller than those at $150 \mathrm{hPa}$ (not shown). To argue statistical significance for separation of the maximum and minimum peaks in Figures 6, 8, 9, and 11, we can follow the $t$ test. The difference between the maximum and minimum is compared with a reference value $(D)$ calculated from a 


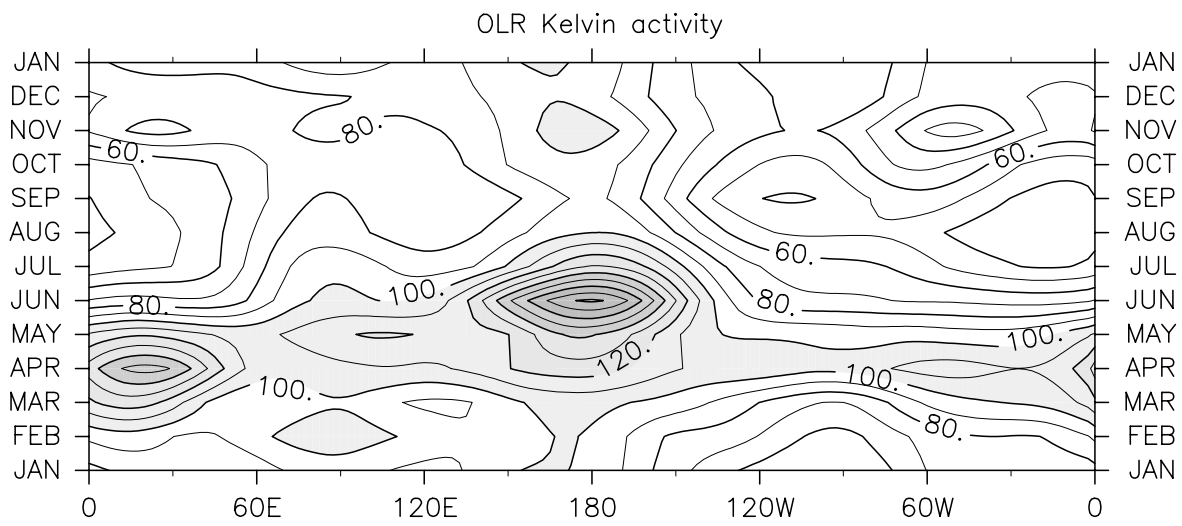

Figure 8. A longitude-time section of the climatological Kelvin wave activities in OLR averaged over latitudes $10^{\circ} \mathrm{S}-10^{\circ} \mathrm{N}$. A contour interval is $10 \mathrm{~W}^{2} \mathrm{~m}^{-4}$, and shading begins above $100 \mathrm{~W}^{2} \mathrm{~m}^{-4}$.

pair of standard deviations at the two points of interest. Since it is not realistic to show these values for any pairs, we calculate $D_{\max }$ from the maximum value of the standard deviations on the whole grid points as a tough criterion. For Figure $6 \mathrm{a}, D_{\max }$ is estimated as 3.6 for the $95 \%$ significance level, so we can safely say the difference between any pair of the peaks larger than 3.6 is statistically significant. In Figure 6a, for example, this can be realized for the longitudinal contrast in February, and for the seasonal contrast around the $60-120^{\circ} \mathrm{E}$ longitude. Those $D_{\max }$ values are calculated for Figures $6 \mathrm{~b}, 8,9$, and 11 as $2.4,36,11$, and 200 , respectively. Since these are very tough criteria, the value would be reduced, if we calculate it for each case of the pairs.

[26] Figure 7a shows a longitude-height cross section of the annual mean Kelvin wave activity in zonal wind. As expected from Figure 6, longitudes of the maximum activity are quite different at each height: The active region is observed in the Eastern Hemisphere at $100 \mathrm{hPa}$, but in the Western Hemisphere around $150 \mathrm{hPa}$ and $200 \mathrm{hPa}$. The maximum values in the Eastern and Western Hemispheres are in a similar order. This feature will be discussed below after presenting a result for the Kelvin wave activity in OLR.

[27] Here we provide some information on Kelvin wave activities seen in the temperature field, though the interpretation is rather difficult in comparison with results from the zonal wind field as described in section 3.2. The seasonal variations in the temperature field are basically similar to those in the zonal wind at $100 \mathrm{hPa}$. However, the activities in the northern summer are higher than the northern winter, because of the change in Brunt-Väisälä frequency $N$. In the annual mean plot (Figure $7 \mathrm{~b}$ ) the maximum appears in the lower stratosphere at $70 \mathrm{hPa}$ and around $60^{\circ} \mathrm{E}$, and this distribution is extended from $100 \mathrm{hPa}$, indicating vertical propagation into the stratosphere. In the upper troposphere at $150 \mathrm{hPa}$, the east-west contrast is not clear, but the longitudinal maximum in the Western Hemisphere is slightly seen at $200 \mathrm{hPa}$ and below. These are also due to the change in Brunt-Väisälä frequency $N$ around the tropopause.

[28] Figure 8 shows a climatological longitude-time section of Kelvin wave activity similar to Figure 6 but for OLR during the period 1979-2002. Figures 8 and 11 (the latter will be shown in section 3.5) are extensions of Wheeler et al. [2000] in a sense that the amplitude in this study (here it is shown in the square amplitude) is estimated at each longitudinal grid point and consequently that the time variations are presented in longitude-time sections. The Kelvin wave activity in OLR is relatively vigorous during northern spring to summer, and there are two distinct maxima: One is between $0^{\circ} \mathrm{E}$ and $50^{\circ} \mathrm{E}$ during March to June and the other around the dateline during May to July; the separated secondary maximum is found between $60^{\circ} \mathrm{E}$ and $120^{\circ} \mathrm{E}$ during February to June.

[29] On the basis of the above results, we discuss on the space-time variation of the Kelvin wave activity around the TTL. As for energy source of vertically propagating Kelvin waves, it is important to supply latent heat released by deep convection. Using radiosonde observations in Indonesia, Shimizu and Tsuda [1997] showed that the phase of Kelvin waves in zonal wind propagates downward above $150 \mathrm{hPa}$, suggesting the energy source of Kelvin waves is located below this level. In addition to the energy source, the background wind condition is important for Kelvin waves to propagate vertically. It is theoretically derived that the Kelvin wave can propagate vertically if $c-U>0$; here $c$ is the zonal phase speed with respect to ground, and $U$ is the background zonal wind. Because the Kelvin wave propagates eastward $(c>0)$, the easterly wind is a favorable condition to propagate vertically. Therefore, two factors are important to understand the seasonal and longitudinal variation of the Kelvin wave activity: One is deep convective activity in relation to the Kelvin wave generation, and the other is background wind situation for the propagation property.

[30] To examine the first factor, we need to look into the Kelvin wave activities seen in zonal wind at $100 \mathrm{hPa}$ (Figure 6a) and $150 \mathrm{hPa}$ (Figure 6b), and the Kelvin wave activities seen in OLR (Figure 8) or deep convective activities (Figure 3). It is clear that vigorous regions of Kelvin wave activities in OLR (Figure 8) or convective activities themselves (Figure 3 ) do not always correspond to those in zonal wind at any of $100 \mathrm{hPa}$ and $150 \mathrm{hPa}$ levels in space and time as partly seen in Figure 5a. Though convection itself might be necessary for Kelvin wave generation, this result suggests that the Kelvin wave activities observed around the tropopause do not always need corresponding convective activities coupled with each other; an idea about the convectively coupled Kelvin wave was first highlighted 


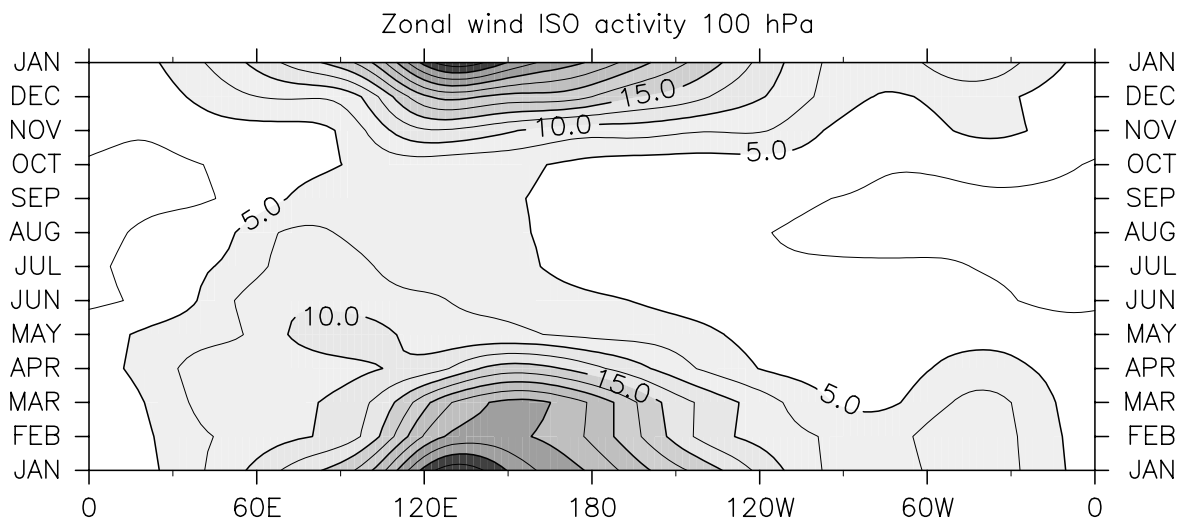

Figure 9. As in Figure 6a except for the ISO component. A contour interval is $2.5 \mathrm{~m}^{2} \mathrm{~s}^{-2}$, and shading begins above $10 \mathrm{~m}^{2} \mathrm{~s}^{-2}$.

by Wheeler et al. [2000] on the basis of the composite analysis referenced to the Kelvin wave variations in OLR.

[31] Another factor to investigate is a relationship between the background zonal wind (Figure 2) and the Kelvin wave activity (Figure 6) around the TTL. As shown in Figure $2 b$ the climatological background zonal winds between $300 \mathrm{hPa}$ and $100 \mathrm{hPa}$ are westerly in the Western Hemisphere and easterly in the Eastern Hemisphere. Kelvin waves in the westerly region possibly suffer damping in the upper troposphere, if the background zonal wind $(U)$ is getting close to the zonal phase speed $(c)$; eventually Kelvin waves with a phase speed equal to the background zonal wind are not able to propagate vertically [e.g., Andrews et al., 1987]. At the same time, the group velocity of Kelvin waves becomes slow and the zonal wind amplitude is increasing, when the background condition is approaching to $c \approx U$. This is why Kelvin wave amplitudes at $150 \mathrm{hPa}$ in zonal wind became large in the Western Hemisphere. On the contrary, Kelvin waves in the easterly region are able to propagate vertically without damping and reach around the tropopause. Then, because of sudden increase in the Brunt-Väisälä frequency $N$, the Kelvin wave amplitude can increase. As to these relations of the background flow and the Brunt-Väisälä frequency to the Kelvin wave amplitude, detailed explanations are given by

(a) Zonal wind ISO activity all seasons

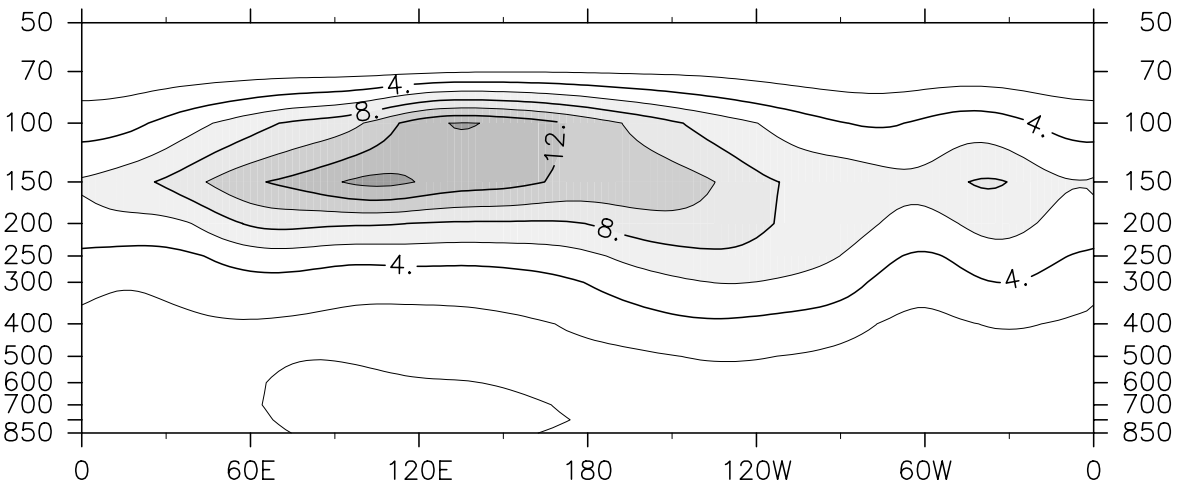

(b) Temp ISO activity all seasons

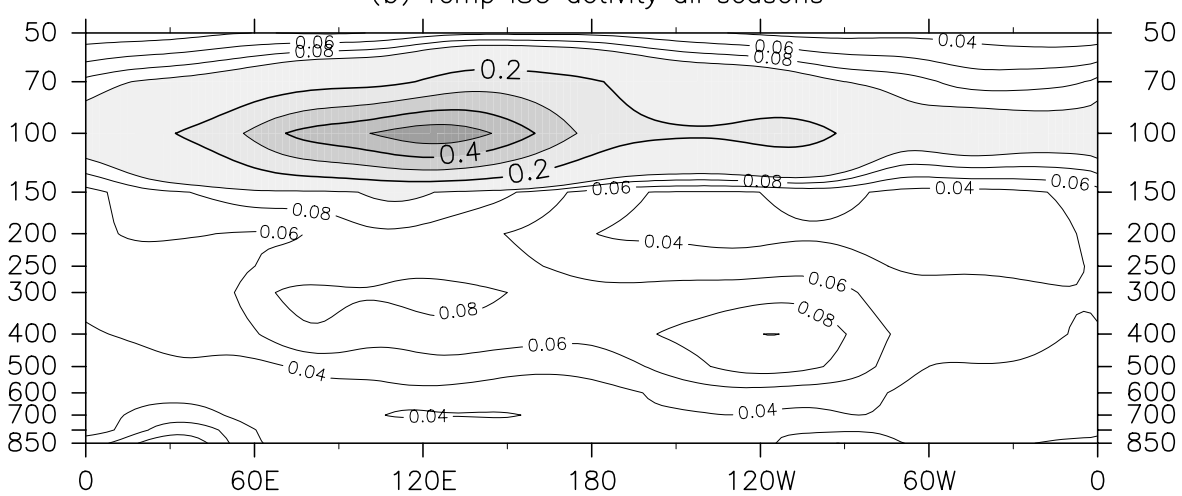

Figure 10. As in Figure 7 except for the ISO components. (a) A contour interval is $2.0 \mathrm{~m}^{2} \mathrm{~s}^{-2}$, and shading begins above $6.0 \mathrm{~m}^{2} \mathrm{~s}^{-2}$. (b) A contour interval is $0.1 \mathrm{~K}^{2}$, and $0.04,0.06$, and $0.08 \mathrm{~K}^{2}$ lines are also drawn. Shading begins above $0.1 \mathrm{~K}^{2}$. 


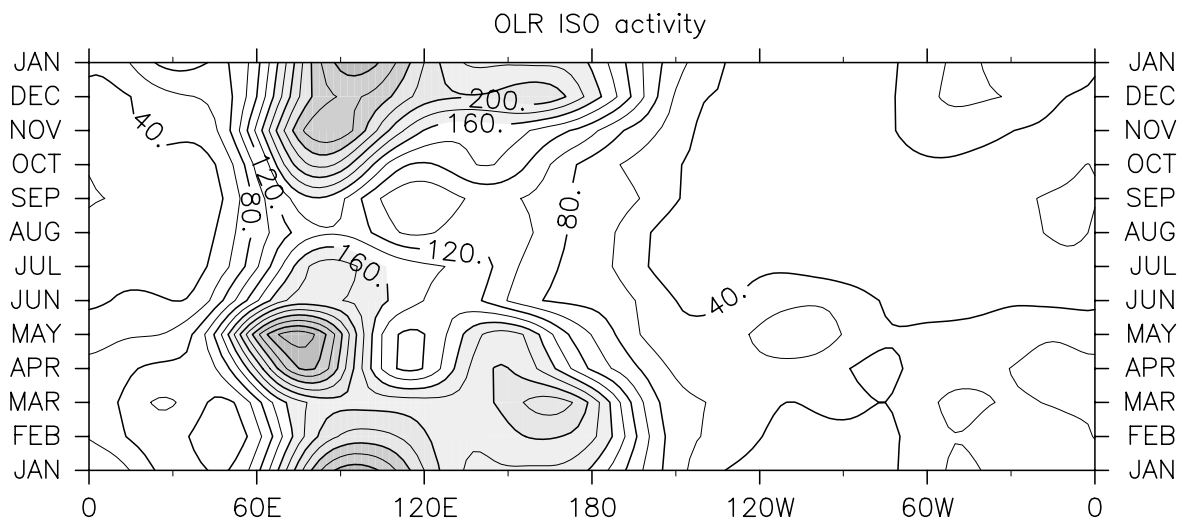

Figure 11. As in Figure 8 except for the ISO component. A contour interval is 20, and shading begins above $160 \mathrm{~W}^{2} \mathrm{~m}^{-4}$.

Shiotani and Horinouchi [1993]. Therefore, the location of maximum activities is higher in the Eastern Hemisphere than in the Western Hemisphere.

\subsection{ISO activity}

[32] Finally we will briefly show ISO activities. Figure 9 shows a climatological time-longitude section as Figure 6 but for the ISO activity at $100 \mathrm{hPa}$. Vigorous ISO activities in zonal wind are highly restricted during northern winter between the Indian Ocean and the Pacific Ocean. Other small maxima are seen around the Atlantic Ocean in January and over the Indian Ocean in May and June.

[33] Figure 10a shows an annual mean longitude-height section as Figure 7a but for the ISO activity in the zonal wind field. Since there is an annual maximum of ISO activities during November-February (Figure 9), the vertical structure of the ISO represents characteristics during northern winter. The ISO activity in zonal wind is vigorous between $250 \mathrm{hPa}$ and $100 \mathrm{hPa}$ pressure levels. Although longitudinal maxima of the ISO activities at $100 \mathrm{hPa}$ and $150 \mathrm{hPa}$ appear almost at the similar region, the most active longitude is somewhat different: at $150 \mathrm{hPa}$ it is active between $60^{\circ} \mathrm{E}$ and $120^{\circ} \mathrm{E}$ but at $100 \mathrm{hPa}$ between $120^{\circ} \mathrm{E}$ and $180^{\circ} \mathrm{E}$. This may suggest that the vertical structure of the ISO tilts eastward with increasing height above the upper troposphere as reported by Kiladis et al. [2005]; their analysis showed distinct differences in the vertical structure at several stations along the MJO phase, and their results seem to be consistent with our representation of the vertical tilt in the western Pacific.

[34] The ISO activity in the temperature field (Figure 10b) is basically similar to that in the zonal wind field (Figure 10a), though the maximum is concentrated at $100 \mathrm{hPa}$. The higher altitude of the maximum in the temperature field than that in the zonal wind filed could be attributed by the change in Brunt-Väisälä frequency $N$ as explained for Figures $7 \mathrm{a}$ and $7 \mathrm{~b}$. The sharp maxima only at $100 \mathrm{hPa}$ suggest insufficient vertical spacing for the analysis in the temperature field.

[35] Figure 11 shows a climatological time-longitude section of the ISO activity as Figure 6 but for OLR during the period 1979-2002. The seasonal variation of the ISO activity in OLR seems to be similar to that of the MJO; Jones et al. [2004] showed that tropical intraseasonal convective activity such as the MJO occurred frequently during April to June and October to December, and infrequently during July to September. The ISO activity in OLR is large between $60^{\circ} \mathrm{E}$ and $180^{\circ} \mathrm{E}$ where the ISO activity in zonal wind is also most vigorous (Figure 9), though the northern summer maximum is larger in OLR than in zonal wind. Moreover the longitudinal maximum in the ISO is located at westward of the ISO maximum in zonal wind. As shown by Eguchi and Shiotani [2004, Figure 2], this feature is also observed in their composite analysis. All these results suggest that the ISO activity in the zonal wind field around the TTL is coupled with the so-called MJO system. The distribution of the Kelvin wave activity in zonal wind at 100 $\mathrm{hPa}$ (Figure 6a) is somewhat similar to that of the ISO activity in OLR (Figure 11). Since convection itself might be necessary for Kelvin wave generation as already mentioned in section 3.4, it is possible that the ISO activities in the OLR is associated with the Kelvin wave activities in zonal wind. Further research is needed to make it clear about the role of MJO-related convections as an energy source of Kelvin waves.

\section{Summary}

[36] Using the ECMWF 40-year reanalysis (ERA-40) data for meteorological fields and the NOAA OLR data as a proxy of convective cloud activity we have investigated temperature and zonal wind variations around the equatorial tropopause, and their relationship to convective activity and background wind field with time scales about a week to 2 months. The space-time spectral analysis was first performed for the temperature and zonal wind fields around the tropical tropopause, and two dominant spectral regions in the eastward propagating domain are found: one for Kelvin waves with zonal wave numbers from 1 to 10 , periods from 4 to 23 days and equivalent depths from 8 to $240 \mathrm{~m}$ and the other for ISOs with wave numbers from 1 to 10 and periods 23 to 92 days.

[37] To investigate space-time variability of Kelvin waves and ISOs we reconstructed the grid data for the two spectral windows through the Fourier forward and inverse transforms, and calculated the square amplitude at each grid point. We mostly focused on the zonal wind field, because the vertical structure in zonal wind is less variable than that 
in temperature; consequently the results for zonal wind seem to be unaffected by the seasonality around the tropical tropopause particularly seen in the temperature field. Kelvin wave activities in zonal wind are vigorous during two seasons, one in January to March and the other in June to August around the upper troposphere up to $100 \mathrm{hPa}$. In contrast, there is a clear difference in the maximum longitude; at $100 \mathrm{hPa}$ it is located in the Eastern Hemisphere from the Indian Ocean to the western Pacific, but at $150 \mathrm{hPa}$ and below it is located in the Western Hemisphere from the eastern Pacific to the South America. To further investigate a relation to deep convection as a source of these disturbances we calculated activities in the OLR data for the Kelvin wave spectral window. Then we found that the activities in OLR do not correspond to those in zonal wind, suggesting that the Kelvin wave activity in zonal wind may not necessarily depend on convection.

[38] As to the change in the maximum altitude of Kelvin wave activities in the upper troposphere we refer to the climatological background zonal wind which is easterly in the Eastern Hemisphere and westerly in the Western Hemisphere. Kelvin waves in the westerly region possibly suffer damping when the background zonal wind is getting close to the zonal phase speed. In such a condition the group velocity slows down, and the zonal wind amplitude is increasing. On the contrary in the Eastern Hemisphere, the amplitude of Kelvin waves propagating vertically in the easterly can increase, because of sudden increase in the Brunt-Väisälä frequency $N$ [Shiotani and Horinouchi, 1993]. Another point to note at $100 \mathrm{hPa}$ is that the maximum Kelvin wave activity is large in the westward of the maximum easterly wind. It would be due to distortion or dissipation of Kelvin waves propagating into the active convective region which is located around the maximum easterly.

[39] The ISO activities in zonal wind at $100 \mathrm{hPa}$ are seen in the western Pacific during northern winter, which are somewhat larger than those of the Kelvin waves. For this spectral window the ISO activities in zonal wind and OLR are related with each other, indicating that the eastward moving disturbance with the ISO time scale is somehow coupled with the organized convective system such as the Madden-Julian oscillation (MJO).

[40] This paper clearly shows seasonal and longitudinal variability in the Kelvin wave and ISO activities around the tropical tropopause. Most analyses were performed for the zonal wind field, but significant variations are also seen in the temperature field. This also suggests that there is possible influence to the dehydration mechanism around the tropical tropopause layer. The long-term variations of the Kelvin wave and ISO activities in relation to the quasi-biennial oscillation (QBO) and the El Niño-Southern Oscillation (ENSO) would be another interesting topic to investigate.

[41] Acknowledgments. We thank N. Nishi for providing valuable comments on this paper. We also thank M. Fujiwara for helpful discussions throughout this work. Data used in this study were obtained from ECMWF for use of the reanalysis at the following archives (http://www.ecmwf.int/). We also thank NOAA/Climate Diagnostics Center for use of the OLR data from their archives (http://www.cdc.noaa.gov/). Figures were created using the GFD-DENNOU Library. This study was supported in part by the Japanese Ministry of Education, Culture, Sports, Science and Technology (MEXT) through the Grant-in-Aid for Scientific Research (11219201, 15204043, 16540398, and 18204041), and the Ministry of the Environment through the Global Environment Research Fund (A-1 and A-071).

\section{References}

Andrews, D. G., J. R. Holton, and C. B. Leovy (1987), Middle Atmosphere Dynamics, 489 pp., Academic, San Diego, Calif.

Dima, I. M., and M. Wallace (2007), Structure of the annual-mean equatorial planetary waves in the ERA-40 reanalyses, J. Atmos. Sci., 64, $2862-$ 2880, doi:10.1175/JAS3985.1.

Eguchi, N., and M. Shiotani (2004), Intraseasonal variations of water vapor and cirrus clouds in the tropical upper troposphere, J. Geophys. Res., 109, D12106, doi:10.1029/2003JD004314.

Fujiwara, M., K. Kita, and T. Ogawa (1998), Stratosphere-troposphere exchange of ozone associated with the equatorial Kelvin wave as observed with ozonesondes and rawinsondes, J. Geophys. Res., 103, 19,103-19,182.

Fujiwara, M., F. Hasebe, M. Shiotani, N. Nishi, H. Vömel, and S. J. Oltmans (2001), Water vapor control at the tropopause by equatorial Kelvin waves observed over the Galápagos, Geophys. Res. Lett., 28, $3143-$ 3146, doi:10.1029/2001GL013310.

Fujiwara, M., M. K. Yamamoto, H. Hashiguchi, T. Horinouchi, and S. Fukao (2003), Turbulence at the tropopause due to breaking Kelvin waves observed by the equatorial atmosphere radar, Geophys. Res. Lett. 30(4), 1171, doi:10.1029/2002GL016278.

Hasebe, F., and H. Koyata (2004), Dynamical properties of the tropical atmosphere derived from radiosonde observations at San Cristóbal and Singapore, J. Meteorol. Soc. Jpn., 82, 1129-1145, doi:10.2151/ jmsj.2004.1129.

Highwood, E. J., and B. J. Hoskins (1998), The tropical tropopause, Q. J. R. Meteorol. Soc., 124, 1579-1604, doi:10.1002/qj.49712454911.

Holton, J. R., M. J. Alexander, and M. T. Boehm (2001), Evidence for short vertical wavelength Kelvin waves in the Department of Energy-Atmospheric Radiation Measurement Nauru99 radiosonde data, J. Geophys. Res., 106(D17), 20,125-20,129, doi:10.1029/2001JD900108.

Jones, C., L. M. V. Carvalho, R. W. Higgins, D. E. Waliser, and J. -K. E. Schemm (2004), Climatology of tropical intraseasonal convective anomalies: 1979-2002, J. Clim., 17, 523-539, doi:10.1175/15200442(2004)017<0523:COTICA $>2.0 . \mathrm{CO} ; 2$

Kiladis, G. N., K. H. Straub, G. C. Reid, and K. S. Gage (2001), Aspects of interannual and intraseasonal variability of the tropopause and lower stratosphere, Q. J. R. Meteorol. Soc., 127, 1961-1983.

Kiladis, G. N., K. H. Straub, and P. T. Haertel (2005), Zonal and vertical structure of the Madden-Julian oscillation, J. Atmos. Sci., 62, 27902809, doi:10.1175/JAS3520.1.

Madden, R. A., and P. R. Julian (1972), Description of global-scale circulation scales in the tropics with a 40-50 day period, J. Atmos. Sci., 29 , 1109-1123, doi:10.1175/1520-0469(1972)029<1109:DOGSCC $>2.0$. $\mathrm{CO} ; 2$.

Madden, R. A., and P. R. Julian (1994), Observations of the 40-50-day tropical oscillation: A review, Mon. Weather Rev., 122(5), 814-837, doi:10.1175/1520-0493(1994)122<0814:OOTDTO >2.0.CO;2.

Nakazawa, T. (1988), Tropical super clusters within intraseasonal variations over the western Pacific, J. Meteorol. Soc. Jpn., 66, 823-839.

Randel, W. J., and F. Wu (2005), Kelvin wave variability near the equatorial tropopause observed in GPS radio occultation measurements, J. Geophys. Res., 110, D03102, doi:10.1029/2004JD005006.

Ratnam, M. V., T. Tsuda, T. Kozu, and S. Mori (2006), Long-term behavior of the Kelvin waves revealed by CHAMP/GPS RO measurements and their effects on the tropopause structure, Ann. Geophys., 24(5), 1355-1366.

Seidel, D. J., R. J. Ross, J. K. Angell, and G. C. Reid (2001), Climatological characteristics of the tropical tropopause as revealed by radiosondes, J. Geophys. Res., 106(D8), 7857-7878, doi:10.1029/2000JD900837.

Shimizu, A., and T. Tsuda (1997), Characteristics of Kelvin waves and gravity waves observed with radiosondes over Indonesia, J. Geophys. Res., 102, 26,159-26,171, doi:10.1029/96JD03146.

Shiotani, M., and T. Horinouchi (1993), Kelvin wave activity and the quasibiennial oscillation in the equatorial lower stratosphere, J. Meteorol. Soc. Jpn., 71, 175-182.

Son, S. W., and S. Lee (2007), Intraseasonal variability of the zonal-mean tropical tropopause height, J. Atmos. Sci., 64, 2695-2706, doi:10.1175/ JAS3982A.1.

Straub, K. H., and G. N. Kiladis (2002), Observations of a convectively coupled Kelvin wave in the eastern Pacific ITCZ, J. Atmos. Sci., 59, 3053, doi:10.1175/1520-0469(2002)059<0030:OOACCK>2.0.CO;2.

Takayabu, Y. N. (1994), Large-scale cloud disturbances associated with equatorial waves, Part I: Spectral features of the cloud disturbances, J. Meteorol. Soc. Jpn., 72, 433-449.

Tindall, J. C., J. Thuburn, and E. J. Highwood (2006), Equatorial waves in the lower stratosphere. II: Annual and interannual variability, $Q . J . R$. Meteorol. Soc., 132, 195-212, doi:10.1256/qj.04.153.

Tsuda, T., Y. Murayama, H. Wiryosumarto, S. W. B. Harijono, and S. Kato (1994), Radiosonde observations of equatorial atmosphere dynamics over Indonesia: 1. Equatorial waves and diurnal tides, J. Geophys. Res., 99, 10,491-10,505, doi:10.1029/94JD00355. 
Uppala, S. M., et al. (2005), The ERA-40 reanalysis, Q. J. R. Meteorol. Soc., 131, 2961-3012, doi:10.1256/qj.04.176.

Webster, P. J., V. O. Magana, T. N. Palmer, J. Shukla, R. A. Thomas, M. Yanai, and T. Yasunari (1998), Monsoons: Processes, predictability and the prospects for prediction, J. Geophys. Res., 103, 14,451-14,510, doi:10.1029/97JC02719.

Wheeler, M., and G. N. Kiladis (1999), Convectively coupled equatorial waves: Analysis of clouds and temperature in the wavenumber-frequency domain, J. Atmos. Sci., 56, 374-399, doi:10.1175/1520-0469(1999)056<0374: CCEWAO $>2.0 . \mathrm{CO} ; 2$.

Wheeler, M., G. N. Kiladis, and P. J. Webster (2000), Large-scale dynamical fields associated with convectively coupled equatorial waves, J. Atmos. Sci. 5, 613-640, doi:10.1175/1520-0469(2000)057<0613:LSDFAW >2.0.CO;2.
Zhou, X., and J. R. Holton (2002), Intraseasonal variations of tropical coldpoint tropopause temperatures, J. Clim., 15, 1460-1473, doi:10.1175 1520-0442(2002)015<1460:IVOTCP $>2.0$.CO; 2 .

Zhou, X., M. A. Geller, and M. Zhang (2001), Tropical cold point tropopause characteristics derived from ECMWF reanalyses and soundings, J. Clim., 14, 1823-1838, doi:10.1175/1520-0442(2001)014<1823:TCPTCD $>2.0 . C O ; 2$.

M. Shiotani, Research Institute for Sustainable Humanosphere, Kyoto University, Gokasho, Uji, Kyoto 611-0011 Japan. (shiotani@rish.kyoto-u. ac.jp)

J. Suzuki, Institute of Observational Research for Global Change, Japan Agency for Marine-Earth Science and Technology, 2-15, Natsushima-cho, Yokosuka-city, Kanagawa 237-0061, Japan. (suzukij@jamstec.go.jp) 